\title{
The eye or the ear?
}

\section{Source language interference in sight translation and simultaneous interpreting}

\author{
Agnieszka Chmiel, Przemysław Janikowski ${ }^{2}$ and \\ Anna Cieślewicz ${ }^{1}$ \\ ${ }^{1}$ Adam Mickiewicz University in Poznań $\mid{ }^{2}$ University of Silesia in \\ Katowice
}

In the current study we set out to investigate source language interference in the visual modality (in sight translation - ST) and in the auditory modality (in simultaneous interpreting - SI). We probed interpretations of cognates, interlingual homographs and passive structures in single sentence contexts as performed from English to Polish by 47 advanced interpreting trainees. We also analysed temporal measures: ear-voice span (in SI) or eye-voice span (in ST) as well as total translation time. The results showed a higher level of interference in ST in the case of homographs and a mixed pattern of results for the remaining measures. We also obtained interesting taskindependent results, namely an $80 \%$ rate of global passive retention testifying to a high level of syntactic priming in both modes of interpreting. We discuss these results in the context of different types of interference occurring in interpreting and conclude that there might be a similar global level of interference in the two tasks, however with differing underlying patterns. This is the first study to date to directly compare interference levels between ST and SI in such controlled conditions. Our results contribute to the understanding of complex linguistic processes occurring across modalities in interpreting tasks.

Keywords: interference, simultaneous interpreting, sight translation, cognates, interlingual homographs

\section{Introduction}

Conference interpreters routinely engage in multitasking carried out in a bilingual or multilingual context. The task demands require of the interpreter to almost 
constantly suppress the activation from the source language input while producing the target language message. Source language lexical items and syntactic structures have to be kept in check so that they do not interfere with the natural sounding of the target language production (Lamberger-Felber \& Schneider 2009; Dailidenaite \& Volynec 2013). Otherwise, the interpreter produces interpretese (Shlesinger 2008), a target language utterance tainted with source language forms through cross-linguistic interference. The input might be either visual (in sight translation, consecutive interpreting with notes and simultaneous interpreting with text) or auditory (in the case of simultaneous interpreting proper and consecutive interpreting). Thus, due to the multitasking and multimodality involved in interpreting practice, interpreters also have to cope with 'resource demand interference', i.e. interference from one task while performing another task due to the competition for limited cognitive resources (Wickens 2002; Seeber 2011). Naturally, as is the case in all tasks in which expertise can be developed, the amount of such interference can be decreased by at least partial automatisation of the simpler sub-processes involved (Strobach \& Schubert 2017).

The present paper aims to examine how the source language affects performance in simultaneous interpreting (SI) and sight translation (ST) to see whether the visual or the auditory input produces more interference. By directly comparing the processing of the same cognates, interlingual homographs and passive structures in both tasks, we will be able to conclude whether interpreters are better able to resist interference from the visual or the auditory modality. Processing auditory stimuli is more linear (i.e. it has to follow the acoustic signal unfolding in time) than processing visual stimuli (that are made available at the same time and may be read or scanned non-linearly) and this might have some ramifications for the temporal parameters of these tasks. Due to different temporal constraints of simultaneous interpreting and sight translation, we also want to examine the temporal dimension of both tasks by comparing lag measures (ear-voice span and eye-voice span).

We would like, however, to first provide an overview of the research to date on both aforementioned types of interference. We start with cross-language interference, which is more directly measurable within the paradigm we adopt. Following this, we outline a working model of the resource-based interference that may partially explain some of the results obtained in our study. Closing the theoretical section, we present the few studies that have already attempted comparisons of the tasks of SI and ST, even if with somewhat differing goals and paradigms. 


\section{Cross-language interference}

According to the classic definition by Weinreich (1953/1979), cross-language interference is a deviation from the norms of one language manifested by bilinguals as a result of language contact. What Weinreich once called language contact has been refined in the concept of cross-language activation, or parallel activation of the two languages of the bilingual (for a review see Kroll et al. 2012: 231-232). Parallel activation happens both when words are processed without context and in sentences (Van Assche et al. 2012). Such activation of both languages that leads to interference has been shown to occur both in comprehension and in production (Spalek et al. 2014) and even across modalities, i.e. in the visual domain when the stimuli are presented aurally (Chéreau et al. 2007).

Despite the abundance of studies and the use of sophisticated techniques such as electroencephalography (EEG) or eye-tracking in some of them, it is difficult to negotiate claims about the underlying behaviour of the cognitive architecture when it operates on two languages. In the strongest and relatively long tradition following Green (1998), language non-specific activation, or activation of both languages, is believed to elicit inhibitory control, allowing the final selection of a unit in the appropriate language for use in comprehension or production. The bulk of evidence for such an explanation is taken from studies employing measurements of response latencies in language switching. With inhibition believed to persist to subsequent trials, the switch costs, i.e. increases in the latencies on trials when languages are switched, are said to reflect the inhibitory control in action (Meuter \& Allport 1999). With such a paradigm, the researchers have been able not only to account for the existence of the postulated inhibition, but also to connect it to the relative dominance of the two languages in the mind of their user (e.g. Costa \& Santesteban 2004). It must be mentioned, however, that there have been attempts to circumvent the need for cross-language inhibition even in models postulating concurrent access to units of both lexicons with alternative solutions involving, for example, boosted activation of the preferred units rather than inhibition of the unwelcome competitors (Verhoef et al. 2009; Runnqvist et al. 2012). Such different approaches, however, seem to have little bearing on interference, which is our main concern here. Whether resolved by boosting activation or by inhibiting it in the competitors, there is ample evidence of the competition itself and we are primarily interested in testing its levels.

In Interpreting Studies, interference is perceived as a negative phenomenon, even deemed contamination of the target text by the source language (Pöchhacker 1994). For some scholars it is one of the most important factors negatively influencing interpreting quality (Seleskovitch \& Lederer 1989) and occurs more in retour interpreting, i.e. interpreting from one's A language to a B language, than 
in interpreting into one's A language (Dailidènaitè \& Volynec 2013). Interferenceridden language used by interpreters has been called interpretese by Shlesinger (2008). The definition of interference applied in this paper is partially based on that by Lamberger-Felber and Schneider (2009:218), who consider interference as a product of the auditory and/or visual influence of the source language on structure and/or elements of the target text. However, we later expand this definition to include other non-linguistic task and capacity factors.

In light of the psycholinguistic research referred to above, interference in interpreting (as in other contexts) might be the result of two mechanisms: crosslanguage activation and inhibition. In simple terms and on a single-word level, once the interpreter sees or hears a word in the source language, the related concepts and their realisations in the target language are activated. The most appropriate translation equivalent might be selected by inhibiting less appropriate competitors and/or by increasing the activation of the desired one.

\subsection{Lexical interference - cognates and homographs}

Lexical interference has often been examined on the basis of words that exist across languages, that is cognates and interlingual homographs (Titone et al. 2011). These items enjoy a special status (Otwinowska 2016) because of their form and/or meaning overlaps. Our understanding of cognates follows that of the psycholinguistic tradition rather than the definition commonly found in linguistics. Cognates are thus defined here as lexical units found across languages that share the semantic meaning and (partially) the form (both orthographic and visual). Thus, they are opposed to interlingual homographs, also referred to as false friends, false cognates or deceptive cognates, which share only the form (cf. Dijkstra et al. 1999; Shlesinger \& Malkiel 2005; Otwinowska 2016).

Because the studies of cognate and homograph processing by interpreters are few in number and limited in scope, we start by briefly reporting on such studies with non-interpreting bilinguals and then review studies involving interpreters and translators.

In the research to date, cognates have been consistently shown to produce facilitation in the form of speeding up the process of lexical retrieval in picture naming (Costa et al. 2000) and word translation (Kroll et al. 2002; García et al. 2014). This facilitation is so robust that it survives even the script change, as has been shown by Hoshino and Kroll (2008) for the Japanese-English language pair. However, there are at least two studies that conversely report costs for cognate words in regular picture naming with language switching tasks. These costs, especially strong in Filippi, Karaminis and Thomas (2014), were only mixed (partial 
facilitation, partial inhibition) in Broersma, Carter and Acheson (2016), which led the latter scholars to the conclusion that:

cognate processing might be affected by two different processes, namely competition at the lexical-semantic level and facilitation at the word form level, and that facilitation at the word form level might (sometimes) outweigh any effects of inhibition at the lemma level (2016: 1).

While cognates might exert both a facilitatory and an inhibitory effect, homographs, in turn, are bilingually costly. Their recognition and production involve greater latencies, compared to control words, their recognition is more errorprone, and neurolinguistic data point to the occurrence of semantic conflict resolution when homographs are processed (Christoffels et al. 2015).

Naturally, cognates and homographs have been a subject of interest to interpreting and translation scholars. In a now classic study on cognates, Shlesinger and Malkiel (2005) asked interpreters to interpret simultaneously and translate texts with English-Hebrew cognates and homophones (taking into account script differences, the similarity was on the phonological level only). In line with their expectations, they found more cognate equivalents in interpreting than translation and greater inhibition of incorrect translations of interlingual homophones in translation as compared to interpreting. They explained these results by pointing to greater demands and stricter time constraints in interpreting as opposed to translation: cognate solutions were more frequently chosen in interpreting because they were the least demanding option. This is in line with the claim made by Gernsbacher and Shlesinger (1997) that processing of homographs and the inhibition of wrong homograph equivalents in interpreting might be negatively influenced by the increased source text speed. In the same vein, the presence of cognates in the interpreter's output is understood by other scholars as a sign of lexical production facilitated by form similarity (Setton 2003; Tercedor 2011).

Two studies to date have focused on cognates in translation. Tercedor (2011) explained the occurrence of cognates in translation through the priming effect. This means that due to form/meaning similarity, cognate equivalents are first activated and immediately selected from among other potential competitors. In the other study, Malkiel (2009) confirmed her hypothesis about translation trainees avoiding the use of cognates. Malkiel also found a negative correlation between cognate avoidance and mistranslation of homophones: trainees who were more sensitive to potential traps related to cognates were more successful in translating homophones.

The studies by Shlesinger and Malkiel (2005); Malkiel (2009) and Tercedor (2011) used close-to-authentic translation and interpreting contexts. Their participants worked on whole texts. More psycholinguistically oriented studies 
(reviewed below) use more controlled paradigms: word translation tasks in which words matched on lexical criteria such as length and frequency are processed in isolation or in sentence context. Similarly to studies on bilinguals, these studies revealed that the cognate facilitation effect was present in word translation performed by interpreters, but Christoffels, de Groot and Kroll (2006) found no statistically significant difference in its size when comparing interpreters to other highly skilled language users (English language teachers). Tymczyńska (2012) examined interpreters, trainees and trilingual controls with a word translation task. The interpreters in her study outperformed the other groups in terms of speed and accuracy. Lijewska and Chmiel (2015) employed a word translation task in sentence context and found no superior performance by trainees compared to controls. Both studies reported a consistent cognate facilitation effect for all groups.

Taken together, these studies show clear patterns. Cognate facilitation (sometimes accompanied by inhibitory costs) and homograph/homophone inhibition are observed across all experimental groups. They manifest themselves in response times, occurrences in translated/interpreted texts and in translation accuracy. Due to their properties, cognates and homographs are interesting items to examine in a study like ours, where we focus on visual and auditory interference. To the best of our knowledge, no previous study has used these items to examine interference when comparing the two synchronous modes of interpreting (SI and ST) that we have selected as our perspective.

\subsection{Structural interference}

According to previous research, in the mind of a bilingual person, syntactic information may be represented in links between lexical representations and combinatorial nodes that specify syntactic structure (Hartsuiker et al. 2004). Such organisation leads to strong cross-language priming effects of structures that are similar in both languages, but also to the preservation of such structures in a TL that does not have them (Maier et al. 2017). The latter study, although not conducted on interpreters or interpreter trainees, was quite similar to the sight translation condition in the present study. Maier et al. (2017) asked highly skilled bilinguals to translate into German an English sentence that was visible on the screen. However, unlike in sight translation proper, the sentence disappeared after $1400 \mathrm{~ms}$, so the source was not visually accessible during the whole translation. The sentences in the Maier et al. study included ditransitive constructions and the participants tended to translate them by retaining the sequence of the objects. The study revealed a high level of cross-language syntactic priming. Using a different paradigm (a dialogue game with a confederate), Fleischer, Pickering 
and McLean (2012) revealed that Polish-English bilinguals were likely to produce English passive structures after Polish passives and active object-verb-subject structures. Fleischer et al. (2012) interpreted these results by claiming that the structural priming results from a similar information structure and a similar order of thematic roles in a sentence.

Studies on structural interference in simultaneous interpreting are rare. Gernsbacher and Shlesinger (1997) suggest that, in order to suppress structural interference, which increases with increased syntactic dissimilarity between languages, interpreters have to manipulate their ear-voice span and both shortening or lengthening it might have disadvantages. In one experimental study, Lamberger-Felber and Schneider (2009) found that morphosyntactic interferences were slightly less frequent than lexical interferences in SI proper and SI with text performed by 12 professional interpreters. Interestingly for our study, they found no significant correlation between the number of interferences produced by the interpreter and the time lag or the length of interpretations. In other words, high occurrence of interference neither shortened nor prolonged the lag and the interpretation itself.

Structural interference has also been researched in translation and interpreting corpora. Teich (2003) even proposed the phenomenon of 'shining through' (understood similarly to SL interference visible in TL) as one of translation universals. Hansen-Schirra (2011) detected 'shining through' on the structural level in a study carried out on comparable and parallel English-German translation corpora. In a more recent study, Wang and Zou (2018) found that front-loaded, attributive modifying structures in Chinese are typically translated into both front- and back-loaded structures in English, resulting in longer and more complex sentences in text interpreted into English compared to original English texts.

Taken together, these studies confirm the occurrence of structural interference both in experiments with bilinguals, interpreters and trainees and in translation and interpreting corpora. Structural interference is a more complex phenomenon to study than lexical interference due to the variations of syntactic structures in (especially typologically different) languages.

\section{Resource demand interference}

Rules of competition for mental resources have been outlined in a number of frameworks, one of the most potent of which is perhaps Wickens's (2002) Multiple Resource Model. It is especially suited for our purposes because both the model and its computational rendering have been adapted for the analysis of SI by Seeber (2011, 2017a). 
In a brief outline, Wickens (2002) postulated that limited resources of the human mind can be grouped into four discrete dimensions, which correspond to the levels of their mutual separation in the cognitive architecture and which translate into differing levels of potential interference between them. The said dimensions are stages (perception and cognition versus production), perceptual modalities (visual versus auditory), visual channels (focal versus ambient) and processing codes (spatial versus verbal).

Based on these divisions, Wickens (2002) postulated that for each task a 'conflict matrix' be developed with weights for interference in each domain calculated on the basis of some further assumptions. Seeber (2011) took Wickens's assumptions along with his exemplary matrix and turned them into a conflict matrix for SI by mapping potential conflicting tasks at different stages of SI and attaching weights to them. In a further reiteration of this model Seeber (2017a) expanded the matrix to include the visual aspects of interpreting, both visual-spatial and visual-verbal as in simultaneous interpreting with text. If directly adapted to ST by a simple subtraction of the auditory verbal dimension and its corresponding conflicts, the updated matrix would suggest the total predicted interference score of 11.3, which is slightly lower than that calculated by Seeber for simultaneous without text (11.6). This, however, would assume simply copying the values of the visual-verbal demand vector and resulting conflict coefficients as if the processing of accompanying text in SI did not differ in the imposed cognitive load and use of resources from that in ST, where it is the sole source of information. Any alterations in this respect already have the potential of globally tipping the scales in 'favour' of cognitive demand in ST. Furthermore, it could be argued that the conflict vector of cognitive verbal vs response verbal resources demand (i.e. the need to process the newly acquired meanings and produce the output version) should have a higher value in ST than in SI. Our reasoning here is that since the cognitive load of inferring meanings from a written text exceeds that of inferring meanings from a comparable spoken text (one reason being the more indirect route that reading takes in our minds - see Sadoski \& Paivio 2013; Tindle \& Longstaf 2015), its overlap with verbal production deserves a higher conflict coefficient in ST, where there are heavy reading constraints. The differences described above, if only tentatively, predict larger global interference proneness of ST compared to SI.

\section{Comparing simultaneous interpreting and sight translation}

It requires no discussion that both sight translation and simultaneous interpreting qualify as highly concurrent and interference-ridden, and by their nature will 
maintain a high level of cross-language co-activation and will involve some mechanisms of control. Yet, differences between them are numerous and substantial and they must influence the relative levels of interference and cognitive load. These differences have been outlined elsewhere, most notably in Agrifoglio (2004). Apart from the obvious 'technical' differences such as the input being oral in SI and written in ST, she also observes the processual contrasts such as speaker- (SI) vs interpreter-paced (ST) nature of the processing, attentionsharing between two audio signals (ST) vs visual input and oral production overlap (ST) or linear as opposed to non-linear reception in SI and ST respectively. Among her features, Agrifoglio (2004) includes some consequences of these differences, that we are actually interested in testing, namely what she calls "high risk of interference" for SI and "extreme risk of interference" for ST (2004: 49).

Previous studies involved in-depth empirical comparisons between these modes of interpreting (Viezzi 1989; Agrifoglio 2004; Lambert 2004) as well as comparisons with other modes of translation (Shreve et al. 2010). At least one of these studies directly focused on levels of interference (Jereščenková 2014). Each of these studies adopted a different perspective and a different set of parameters, none overlapping with ours. Among them, Lambert (2004) is perhaps the worthiest of note, as it is the only one in which the results of the comparison seem to consistently suggest that there is a benefit to ST compared to SI in terms of the ease of processing (and hence a smaller level of interference in ST). In her study, Lambert asked trainees to sight translate, simultaneously interpret (with text) and then simultaneously interpret (without text) portions of the same speech. Additionally, ST and SI with text were preceded by ten-minute preparation periods when the text was made available to the participants. Lambert's results showed a statistically significant difference in "performance scores" with performance in ST evaluated by three independent judges as significantly better than in SI, thus suggesting that the visually available text boosts performance.

Unfortunately, the actual scoring method is not provided in this study, making it impossible to assess whether some confounding has not occurred at this stage. Another confounding factor limiting the reliability of Lambert's results is the potential fatigue effect experienced by the students. All participants in the study interpreted in the same sequence with no counterbalancing of task order. But perhaps the greatest reservation against the reliability of Lambert's results stems from the preparation time her participants were provided with before performing the sight translation task. This extra time amounted to 10 minutes spent with text compared to just five minutes of its actual interpreting. With this amount of preparation time, the participants might well have tracked the structural relationships between central propositions of the text and may even have disambiguated any local miscomprehensions as well as activated translation equivalents 
for the most demanding units. This would have turned the task into a game of cued retrieval of memory traces for sequences of propositions, a task substantially different from pure ST that we are interested in.

Apart from Lambert, Agrifoglio (2004) conducted a study in which an ST condition was preceded by preparation time. In her case, the participants were professional interpreters and the comparison was made between different modes (consecutive interpreting was included, simultaneous with text was not), but the two conditions of interest to our study, namely ST and SI, were included. Agrifoglio split her analysis of errors into meaning and expression failures and achieved a more fine-grained picture of the interpreting difficulties. ST showed the opposing trends of the greatest number of expression errors and the smallest number of meaning errors of all the three conditions tested.

In contrast, Viezzi (1989) concentrated on content only and measured information retention following listening, reading aloud, SI and ST. What is important to note is that, in his case, the ST condition was 'pure' with no preparation time given to either interpreting students or professional interpreters. The results he achieved were contrary to that of Lambert (and partially Agrifoglio), with ST resulting in the lowest scores of all tested conditions for both groups.

Finally, and perhaps most interestingly, Jereščenková (2014) specifically concentrated on what she defined as interference errors. Although her results must be taken with caution, because her sample of participants was very small (only six trainees with highly differing language profiles), in her comparison of ST and SI, she found almost twice as many instances of interference in ST as in SI even despite the fact that, in her case, ST was preceded by five minutes of preparation and with explanation of potentially problematic terms. On the other hand, the SI input was at a very slow rate of 69 words per minute and terminology was also explained beforehand in this case. Although the author is, naturally, very cautious in forming any pronounced conclusions, it is interesting to observe that the pattern of more interference in ST was observed in all participants and it held for most categories, although it was most visible in the case of lexical interferences and word order calques.

The above studies are very difficult to compare because of the differing variables; however, taken together, the findings seem to show an emerging pattern of ST (especially without preparation) resulting in more erroneous target texts than in SI. In explaining this pattern, those authors who share this view repeatedly point to the problem of greater visual interference due to sustained presence of the visual text in ST (Agrifoglio 2004; Shreve et al. 2010). A particularly attractive hypothesis as to the mechanism explaining the more erroneous output in ST, is the depth of processing hypothesis, perhaps best summarised in the following quote from Shreve et al. (2010:65): 
Because the written source text remains available to sight translators, they are not "forced," as interpreters are, to process the information in the text at deeper levels. The transient nature of the interpreter's oral input requires a deeper and more meaningful processing of the input into memory if the interpreting task is to succeed at all.

In other words, the cross-modal interference resolution for ST might be posited to occur by lessening the demand on processing the written text. By making the processing shallow, the interpreter, and especially the trainee, is able to devote more attention to the TL version production.

Such a potential explanation is well in line with the good enough processing theory of sentence comprehension (Ferreira \& Patson 2007). This theory assumes that comprehenders do not usually process information they receive in a manner that is detailed, complete and accurate with regard to the input. Instead, they usually rely on a 'good enough', shallow interpretation achieved with less effort. The 'good enough' approach in interpreting may at first be surprising, because an idealised picture of interpretation assumes perfect comprehension at all times, but let us keep in mind that interpreting decisions are made under enormous cognitive constraints that may additionally lead to somewhat compromised monitoring. Thus, it is not at all unlikely that sight translators do rely on such a simplified understanding of the texts they are working with. This may especially be so with those who are not yet seasoned professionals, but fresh graduates or interpreting students (as was the case in all the studies reviewed above apart from Agrifoglio and a subsample in Viezzi's).

\section{The present study}

The main aim of the present study was to examine if interpreting trainees are more prone to interference from the source language in interpreting if the source language is presented visually (in ST) as compared to auditory presentation (in SI). For that purpose, we asked interpreting trainees to perform sight translation and simultaneous interpreting. The interference was measured on the lexical and structural level. As regards the lexical level, the experimental sentences to be sight translated or interpreted by the participants included cognates and interlingual homographs. Cognates could be rendered by using either a cognate or a noncognate translation equivalent, while interlingual homographs had to be rendered by using a non-cognate equivalent since the target language homograph equivalent was an incorrect translation. As regards the structural level, the sentences included agentless passive constructions. Passive voice is more common in English than in Polish and it is frequently overused in English-Polish translations, 
especially by inexperienced translators (Hejwowski 2004). In the present study, agentless passive structures could be rendered into Polish either by means of a similar syntactic structure (which is grammatically correct but stylistically less natural) or by means of an impersonal active structure (which is a more natural stylistic choice).

We predicted that visually presented stimuli would affect the participants' performance more than auditory stimuli, that is that the participants would be more prone to source language interference in ST than in SI. More specifically, we expected that cognates would be rendered via their cognate translation equivalents more often in ST than in SI. We predicted that interlingual homographs would be translated less accurately in ST as compared to SI, i.e. there would be more instances of wrong renditions via target language homograph forms. In the case of the structural interference, our prediction was that the source text structure would be retained more in ST resulting in lower quality stylistic choices in the output while it would not be preserved as much in SI, resulting in more naturally sounding renditions. Our predicted higher occurrence of interference-based renditions in ST as compared to SI was based on the depth of processing hypothesis (Shreve et al. 2010) and good enough processing hypothesis (Ferreira \& Patson 2007) reviewed above.

In the present study, we also wanted to measure temporal aspects of both modes of interpreting and thus we included time lag and translation time as two additional dependent variables. The time lag measure was operationalised as earvoice span in SI (understood as the delay between the onset of the source language sentence and the onset of the interpreter's output) and eye-voice span in ST (understood as the delay between the beginning of the visual presentation of the source language sentence and the onset of the interpreter's output). Based on the tenets of the Multiple Resource Model (Wickens 2002) and its application to ST modelled after Seeber's (2011, 2017a) cognitive load model in SI, we assumed that the overall cognitive demand caused by interference in ST should exceed that of SI despite the fact that a modality is not shared in this type of interpreting. Hence, we predicted that the time lag would be longer in ST than in SI.

The other temporal measure was translation time calculated as the time in which the participants produced their output. We expected longer translation times in ST as compared to SI because ST is an interpreter-paced rather than speaker-paced task so the time constraints are less strict and because there is more interference to inhibit from the visual modality as opposed to the auditory modality in SI. Additionally, we predicted that translation time would be shorter for sentences with interference-based equivalents (cognates and retained passive structures) as these solutions would not entail delays due to inhibition of the interference. 


\subsection{Participants}

The participants were 47 ( 34 female and 13 male) advanced students of conference interpreting from three language faculties at two Polish universities with Polish as their A language and English as their B language. They were all completing their second year of a two-year master's programme. Their mean age was 24.06 $(S D=1.03)$. They had received approximately 360 hours of practical training in Polish-English and English-Polish consecutive and simultaneous interpreting prior to the study. The participants' average score on the LexTALE test (Lemhöfer \& Broersma 2012) was $82.35 \%(S D=8.14)$, which means their English was at an advanced level. The participants also took a self-reported language competence test in which they rated their current ability in reading, writing, speaking and listening for all languages they knew; the rating was on the scale from 1 (very poor) to 7 (native-like). The results of the questionnaire for Polish and English are presented in Table 1.

Table 1. Means (standard deviation in parentheses) of a self-reported language competence test

\begin{tabular}{lcccc}
\hline & Reading & Writing & Speaking & Listening \\
\hline A (L1, Polish) & $6.82(0.37)$ & $6.65(0.56)$ & $6.63(0.60)$ & $6.76(0.51)$ \\
B (L2, English) & $5.97(0.76)$ & $5.48(0.80)$ & $5.42(0.82)$ & $5.48(0.99)$ \\
\hline
\end{tabular}

Some participants reported competence in other languages, including German, French, Chinese and Japanese.

\subsection{Materials}

Experimental words included 20 English-Polish cognates (e.g. barrier) and 20 words that were interlingual homographs in English and Polish (e.g. billion). Cognates were selected so that they could be correctly interpreted into Polish by means of a cognate equivalent (e.g. bariera) or a non-cognate equivalent (e.g. przeszkoda). Homographs could be correctly interpreted into Polish only by means of a non-homograph equivalent (e.g. miliard) and the homograph equivalent was not a correct translation (e.g. bilion). The English words were matched for length, frequency and concreteness according to SUBTLEX-UK (Van Heuven, Mandera, Keuleers \& Brysbaert 2014). Additionally, the length and frequency of Polish translation equivalents (both cognate and non-cognate translation equivalents for cognates and incorrect homograph and correct non-homograph translations for homographs) were matched on the basis of SUBTLEX-PL (Mandera, 
Keuleers, Wodniecka \& Brysbaert 2015) since these two characteristics have a major influence on lexical processing (Van Heuven et al. 2014). The stimuli were divided into two sets, A and B, each set consisting of 10 cognates and 10 interlingual homographs. The words in the sets were distributed evenly according to their properties so that the two sets were matched (see Table 2).

Table 2. Overall characteristics of experimental words

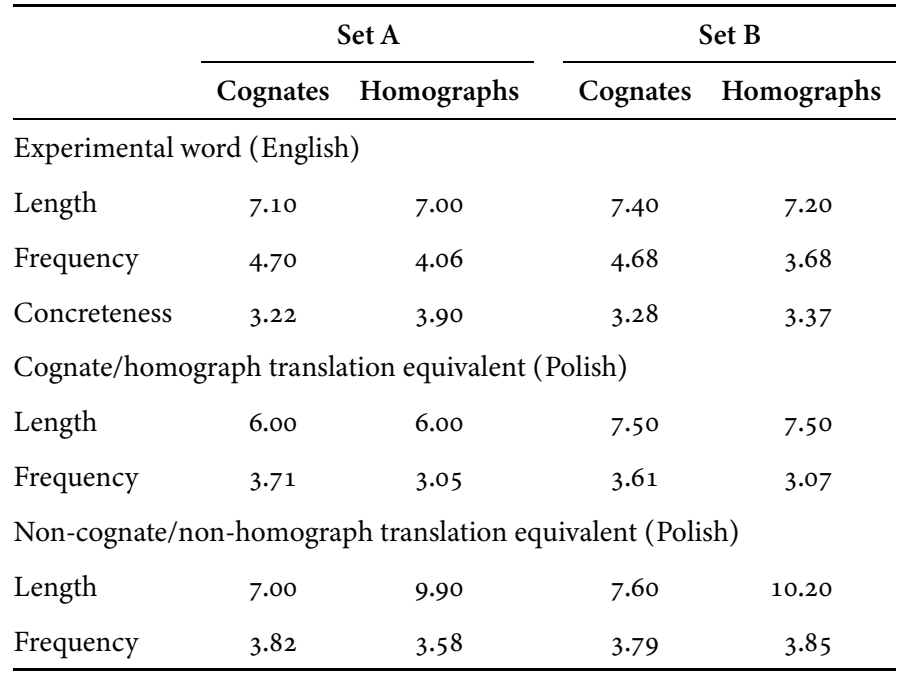

Sentences were constructed around each word in order to provide context. The sentences were between 75 and 91 characters long (mean: 84.15 characters). Their difficulty was measured with the Gunning Fog Index and ranged between 11.31 and 14.43 (mean: 12.22). They were simple sentences with no more than three three-syllable words. The sentences were not related to each other. Each set also included 10 additional sentences with passive voice without an agent. These sentences were between 74 and 93 characters long (mean: 84.35) and their difficulty measured with Gunning Fog Index ranged between 11.31 and 14.80 (mean: 11.95). Table 3 presents sample experimental sentences.

Table 3. Sample experimental sentences

\begin{tabular}{ll}
\hline $\begin{array}{l}\text { Interlingual } \\
\text { homograph }\end{array}$ & $\begin{array}{l}\text { My cousin lives in a poorly decorated apartment on small pension and } \\
\text { his wife's earnings. }\end{array}$ \\
$\begin{array}{l}\text { Cognate } \\
\text { She missed a chance for promotion when she turned down the job for a } \\
\text { senior analyst. }\end{array}$ \\
$\begin{array}{l}\text { Agentless passive } \\
\text { structure }\end{array}$ & $\begin{array}{l}\text { Her application for the loan was rejected because she did not meet all the } \\
\text { requirements. }\end{array}$ \\
\hline
\end{tabular}


The sentences were then recorded by an American native speaker; the speed of delivery was 98 words per minute which is considered easy to comprehend and interpret (Setton \& Dawrant 2016; Seeber 2017b).

\subsection{Procedure}

The experiment was programmed and run in E-Prime software (Schneider, Eschman \& Zuccolotto 2002). The participants were asked to sight translate 30 sentences and simultaneously interpret 30 sentences. There were four different versions of the experiment with a counterbalanced order of tasks (ST vs. SI) and a randomised presentation of sentences. If the participant sight translated set A, then they simultaneously interpreted set B, and vice versa. Each session began with a short practice block with a different set of sentences so that the participants could get used to the procedure.

The participants' interpreting performance was recorded with a single-track system; the beginning of the recording was time-aligned with the moment the participants began to hear or see the sentence appear on the screen. At the end of the experiment the trainees were asked to fill in a short self-reported language competence questionnaire and a LexTALE test. Each experimental session lasted approximately 25 minutes.

\section{Results}

We first removed all the instances of missing translations of the experimental items. We also removed those translations of cognates and homographs that did not involve cognate/homograph or non-cognate/non-homograph equivalents (e.g. imprecise translations and generalisations were excluded from the analysis). As a result, $11 \%$ of all data had to be removed. Over two-thirds of these removed observations were from the simultaneous interpreting task, which testifies to high cognitive load triggered by this type of interpreting.

We first analysed the translations of cognates. They could be rendered in Polish either as cognates (e.g. barrier - bariera) or as non-cognates (e.g. barrierprzeszkoda). Both translations were correct. We calculated both cognate and noncognate translations in both tasks. In ST, cognates were rendered by means of their cognate equivalents in $57 \%$ of cases and by means of non-cognates in $43 \%$ of cases. For SI, these figures were similar: $56 \%$ and $44 \%$, respectively.

To see if there was an association between the type of translation used by the participants and the type of task, we performed Pearson's Chi-square test with Yates' continuity correction. There was no significant association between the 
translation used and the task $\left(X^{2}(1)=0.19, p>.05\right)$. Thus, the way cognates were translated was not dependent on whether the task was ST or SI.

We then proceeded to the analysis of the homograph data. We calculated translation accuracy by giving 1 point for a non-homograph translation of the homograph (e.g. lecture - wykład), which is a correct translation, and o points for a homograph translation (e.g. lecture - lektura), which is an incorrect translation. We then fitted a linear mixed model with accuracy score (ranging from 1 for 100 percent accuracy to o for o percent accuracy for all sentences) as a dependent variable, task as a fixed factor and participants as a random factor. The analysis revealed a significant effect of task $(b=.06, t=2.52, p<.05)$, showing greater accuracy in SI $(M=.89)$ as compared to ST $(M=.82)$. This suggests that translations employing wrong solutions were more frequent in ST. We also analysed these data similarly to the data on cognates. That is, we calculated homograph and non-homograph translations in both tasks. There were $18 \%$ of homograph and $82 \%$ of non-homograph renditions in ST and $11 \%$ of homograph and $89 \%$ of nonhomograph renditions in SI. We then performed Pearson's Chi-square test, which showed an association between the translation solution and task $\left(X^{2}(1)=5.81\right.$, $p<.05)$.

We performed a similar analysis of passives and calculated how many times passive voice was retained in ST and SI (which is a permissible but less stylistically accurate solution in the target language), and how many times it was replaced by another construction (with active voice or an impersonal structure), which is a much more natural-sounding solution. $18 \%$ of passives were changed and $82 \%$ were retained in ST. In SI, 9\% of passives were changed and 91\% were retained.

Despite numerical differences, the Chi-square test revealed no association between the type of translation (changed vs. retained) and the type of task (ST vs. SI) $\left(X^{2}(1)=1.56, p>.05\right)$, suggesting that the passive voice was not retained significantly more often in ST as compared to SI. Although the difficulty of our experimental sentences was well matched, it still showed some variability. Thus, in order to see if the retention or change of the passive construction could possibly depend on the difficulty of the sentence, we fitted a logistic regression model with the Gunning Fog Index value as a continuous fixed factor and participants as a random intercept. The difficulty of the sentence did not predict the structure used in translation $(z=-1.546, p=0.12)$.

We then analysed both temporal measures. In order to arrive at a normal distribution of data, we visually inspected it and excluded time lag measures longer than $2.000 \mathrm{~ms}$ as outliers. This resulted in the exclusion of $8 \%$ of data. A linear mixed model was fitted with task and LexTALE results as fixed factors and participants as random intercepts. It revealed a significant effect of task $(b=-81.33$, 
$t=-3.79, p<.001)$. The time lag was shorter in SI $(M=919 \mathrm{~ms}, S D=578)$ than in ST $(M=1015 \mathrm{~ms}, S D=538)$.

Translation time measures longer than $2200 \mathrm{~ms}$ were excluded as outliers following the visual inspection of data in order to normalise its distribution. This resulted in the exclusion of $9 \%$ of data. A linear mixed model was fitted with task and LexTALE results as a fixed factor and participants as random intercepts. It revealed a significant effect of task $(b=156.39, t=5.96, p<.001)$. The translation time was longer in SI $(M=1211 \mathrm{~ms}, S D=635)$ than in ST $(M=1052 \mathrm{~ms}, S D=633)$. In order to determine if translation times depended on whether the participants used interference-based equivalents (cognates, homographs and retained passive structures respectively) or non-interference-based ones (non-cognates, nonhomographs and changed structures respectively), we fitted additional models separately for cognates, homographs and passives. Each linear mixed model had translation output (interference-based or not) as a fixed factor and participants as random intercepts. Contrary to our predictions, none of the fixed factors turned out to be significant (all ps $>.05$ ), suggesting that translation times did not shorten when the participants used cognate/homograph equivalents or retained the passive structure.

We also conducted regression analyses to see if English proficiency (LexTALE scores) could predict total accuracy (for all experimental items) and accuracy in translating homographs (i.e. sensitivity to false friends) in particular. We found that English proficiency predicted neither total accuracy $(b=.18, t=1.34, p>.05)$ nor accuracy in homograph translation $(b=.36, t=1.58, p>.05)$. This might show a dissociation between proficiency and translation expertise or stem from insufficient sensitivity of the LexTALE test when assessing highly proficient levels of language competence.

\section{Discussion}

This study focused on comparing visual and auditory interference in sight translation and simultaneous interpreting. We generally predicted more interference in processing cognates, homographs and passives in ST than in SI. Our predictions were partially confirmed.

Contrary to our expectations, there was no effect of task in the renditions of cognates. Cognate equivalents were used similarly in ST and SI. In fact, there was no clear preference for cognate or non-cognate solutions in either task, which is not in line with the trend to avoid using cognates revealed, albeit in written translation, by Malkiel (2009). This result is also at variance with the findings by Shlesinger and Malkiel (2005) who revealed more cognates used in a more 
difficult mode - this might be partially due to different tasks used in that study (written translation and SI) and different participants (professional interpreters).

The results confirmed our predictions regarding interlingual homographs wrong homograph equivalents were used more often in ST than in SI. However, it should be noted that the participants, although trainees, reached a fairly high accuracy rate of over $80 \%$ in both tasks. This lends support to the findings by Jereščenková (2014) who reported more lexical interference in ST as compared to SI. However, this contradicts the results of Agrifoglio (2004) who discovered fewer meaning errors in ST than in SI, and those of Lambert (2004) who reported overall better quality in ST. Following psycholinguistic literature (e.g. Titone et al. 2011; Christoffels et al. 2015), we might assume that both cognate and non-cognate competitors are activated when the interpreter hears or sees a cognate or a homograph. According to our results, the modality does not affect the selection of the equivalent in the case of cognates. As regards homographs, however, interference stemming from the activated wrong homograph equivalent is greater in the visual modality, resulting in less successful inhibition.

Our predictions were not confirmed as regards structural interference. The passive voice was retained equally often in ST and SI, which contradicts Agrifoglio (2004) who reported more expression errors in the visual modality compared to SI, and Jereščenková (2014) who found more structural interference (operationalised as word order calques) in ST than in SI. However, one has to bear in mind that these two studies used different measures of interference than those in the present study. Furthermore, the participants retained an overwhelming majority of the passive constructions (over $80 \%$ in either task), which might suggest that trainees are not experienced enough to focus on translation choices that are more stylistically elegant and natural. Instead, due to limited resources, they opt for the simplest solution and employ the source language structure in the target language since it is grammatically correct. Such a strategy is applied regardless of the task type and it might be due to effort saving. It would be interesting to compare these results with those from professional interpreters to see if expertise leads to the choice of strategies leading to more stylistically appropriate versions. The structural interference present in both tasks (in line with psycholinguistic studies showing such interference in translation (Maier et al. 2017) and verbal production (Fleischer et al. 2012)) might be explained by the good enough processing theory (Ferreira \& Patson 2007) and the least effort expended by the trainees in cognitively demanding and highly constrained tasks.

Our accuracy findings show an interesting pattern. Interference-based solutions were more frequent in ST than in SI only if they resulted in inaccurate translation (homographs). We found no effect of task where interference-based solutions were as accurate as non-interference-based ones (in the case of cog- 
nates) or only stylistically, but not denotatively, inferior to non-interference-based solutions (in the case of passives). This might point to a costly processing of homographs in terms of inhibition demands. It would be interesting to directly compare cognates and homographs in a fully orthogonal study design (cognates and homographs would have to be embedded in the same sentences) to see how SI and ST task demands modulate activation and inhibition in lexical processing.

As regards our temporal measures, we expected that the time lag would be longer in sight translation than in simultaneous interpreting. This was indeed the case. This result might be explained by the higher cognitive demand caused by interference in ST in line with the Multiple Resource Model (Wickens 2002). However, it might also be related to the fact that SI is not interpreter-paced so the trainees tend to start interpreting earlier than in ST for fear of overloading their memory buffer and losing track of what has been said.

Contrary to our predictions, translation time was longer in SI than in ST. This might result from the overall higher cognitive load entailed by SI, which was also confirmed in missing or inaccurate translations removed in our analysis (over two-thirds of them were from the SI task). We also expected translation times to be longer for sentences with non-interference-based equivalents (non-cognates and changed passives) due to inhibition of the interference and the lack of cognate facilitation effect. This was not confirmed: the type of translation equivalents (interference-based or not) did not affect translation times. This might go against literature reporting cognate facilitation effects (Kroll et al. 2002; García et al. 2014; Christoffels et al. 2015), but we have to remember that such studies are usually based on single word tasks. Sentence context (present in our experimental paradigm) might modulate or even offset cognate facilitation and homograph inhibition effects so that they are no longer visible. Our results lend support to the findings by Lamberger-Felber and Schneider (2009) who also found no association between interference and interpretation length. Although language proficiency was not a variable manipulated in the study, our analysis delivered an interesting finding. It showed a potential dissociation of language competence and translation competence.

To the best of our knowledge, it is the first study to date with such a study design, which makes it difficult to compare to previous studies with different paradigms. In the future, it would be interesting to use a similar experimental setup to further investigate lexical interference (with a more orthogonal design to directly compare cognates, homographs and control words) and structural interference (with manipulated sentence structures and meaningful units to further examine restructuring and temporal measures). Obviously, a limitation of this study was that - although it used a relatively large sample of 47 participants - it involved only trainees with no between-groups comparison with professional interpreters. 
Another possible limitation was the source text speed (very low according to modern simultaneous interpreting standards). The source speech rate should be higher in any future replications of the study involving professional interpreters.

To conclude, our initial hypotheses regarding greater visual interference in sight translation as compared to auditory interference in simultaneous interpreting have been statistically supported only in the homograph condition. The results for cognates and passive structures, despite being numerically in line with our hypotheses, did not reach statistical significance and must be rejected. A truly surprising result, however, is the very high rate (reaching $80 \%$ in both tasks) of preserving passive structures despite their being less stylistically acceptable in the Polish language and despite the high linguistic competence of our participants. Assuming a demand-related cause, this testifies, at the very least, to the high cognitive demands both ST and SI put on the interpreters; however, this should be tested in a study involving professional interpreters.

Globally, we are inclined to cautiously interpret our results as testifying either to the same global level of processing interference in both interpreting tasks but with different underlying patterns or to there being a difference (perhaps in favour of more interference in ST), but very difficult to tease apart due to the sophistication of both processes and the multitude of individual factors and strategies employed to cope with interference. Certainly, more research is needed, including that involving professional interpreters.

\section{References}

Agrifoglio, M. (2004). Sight translation and interpreting: A comparative analysis of constraints and failures. Interpreting 6 (1), 43-67. https://doi.org/10.1075/intp.6.1.05agr

Broersma, M., Carter, D. \& Acheson, D. J. (2016). Cognate costs in bilingual speech production: Evidence from language switching. Frontiers in Psychology 7, 1-16. https://doi.org/10.3389/fpsyg.2016.01461

Chéreau, C., Gaskell, M.G. \& Dumay, N. (2007). Reading spoken words: Orthographic effects in auditory priming. Cognition $102(3), 341-360$.

https://doi.org/10.1016/j.cognition.2006.01.001

Christoffels, I.K., de Groot, A. \& Kroll, J.F. (2006). Memory and language skills in simultaneous interpreters: The role of expertise and language proficiency. Journal of Memory and Language 54 (3), 324-345. https://doi.org/10.1016/j.jml.2005.12.004

Christoffels, I., Timmer, K., Ganushchak, L. \& Heij, W.L. (2015). On the production of interlingual homophones: Delayed naming and increased N40o. Language, Cognition and Neuroscience 31 (5), 1-11.

Costa, A., \& Santesteban, M. (2004). Lexical access in bilingual speech production: Evidence from language switching in highly proficient bilinguals and L2 learners. Journal of Memory and Language 50 (4), 491-511. https://doi.org/10.1016/j.jml.2004.02.002 
Costa, A., Caramazza, A. \& Sebastian-Galles, N. (2000). The cognate facilitation effect: implications for models of lexical access. Journal of Experimental Psychology: Learning, Memory, and Cognition 26 (5), 1283-1296.

Dailidènaite, A. \& Volynec, J. (2013). Source language interference with target language in conference interpreting. Vertimo studijos. Research Journal for Translation Studies 6, 34-49.

Dijkstra, T., Grainger, J. \& van Heuven, W. J. B. (1999). Recognition of cognates and interlingual homographs: The neglected role of phonology. Journal of Memory and Language 41 (4), 496-518. https://doi.org/10.1006/jmla.1999.2654

Ferreira, F. \& Patson, N.D. (2007). The 'good enough' approach to language comprehension. Language and Linguistics Compass 1 (1-2), 71-83. https://doi.org/10.1111/j.1749-818X.2007.00007.x

Filippi, R., Karaminis, T. \& Thomas, M.S.C. (2014). Language switching in bilingual production: Empirical data and computational modelling. Bilingualism: Language and Cognition 17 (02), 294-315. https://doi.org/10.1017/S1366728913000485

Fleischer, Z., Pickering, M. J. \& McLean, J.F. (2012). Shared information structure: Evidence from cross-linguistic priming. Bilingualism: Language and Cognition 15 (3), 568-579. https://doi.org/10.1017/S1366728911000551

García, A. M., Ibáñez, A., Huepe, D., Houck, A.L., Michon, M., Lezama, C. G., Chadha, S. \& Rivera-Rei, Á. (2014). Word reading and translation in bilinguals: The impact of formal and informal translation expertise. Frontiers in Psychology 5, 1-14.

Gernsbacher, M.A. \& Shlesinger, M. (1997). The proposed role of suppression in simultaneous interpretation. Interpreting 2 (1-2), 119-140. https://doi.org/10.1075/intp.2.1-2.05ger

Green, D.W. (1998). Mental control of the bilingual lexico-semantic system. Bilingualism: Language and Cognition 1 (02), 67-81. https://doi.org/10.1017/S1366728998000133

Hansen-Schirra, S. (2011). Between normalization and shining-through: Specific properties of English-German translations and their influence on the target language. In S. Kranich, V. Becher, S. Höder, \& J. House (Eds.), Multilingual discourse production: Diachronic and synchronic perspectives. Amsterdam: John Benjamins, 133-162. https://doi.org/10.1075/hsm.12.07han

Hartsuiker, R. J., Pickering, M.J. \& Veltkamp, E. (2004). Is syntax separate or shared between languages? Cross-linguistic syntactic priming in Spanish-English bilinguals. Psychological Science 15 (6), 409-414. https://doi.org/10.1111/j.0956-7976.2004.00693.x

Hejwowski, K. (2004). Translation: A cognitive-communicative approach. Olecko: Wydawnictwo Wszechnicy Mazurskiej.

Hoshino, N. \& Kroll, J.F. (2008). Cognate effects in picture naming: Does cross-language activation survive a change of script? Cognition 106 (1), 501-511. https://doi.org/10.1016/j.cognition.2007.02.001

Jereščenková, A. (2014). Interferenzen beim Vom-Blatt-Dolmetschen und beim Simultandolmetschen. MA thesis, University of Vienna.

Kroll, J.F., Dussias, P.E., Bogulski, C.A. \& Kroff, J.R.V. (2012). Juggling two languages in one mind. In B.H. Ross (Ed.), Psychology of learning and motivation (Vol. 56). Oxford: Academic Press, 229-262. https://doi.org/10.1016/B978-0-12-394393-4.00007-8

Kroll, J.F., Michael, E., Tokowicz, N. \& Dufour, R. (2002). The development of lexical fluency in a second language. Second Language Research 18 (2), 137-171.

https://doi.org/10.1191/0267658302sr2010a 
Lamberger-Felber, H. \& Schneider, J. (2009). Linguistic interference in simultaneous interpreting with text: A case study. In G. Hansen, A. Chesterman \& H. Gerzymisch-Arbogast (Eds.), Efforts and models in interpreting and translation research. A tribute to Daniel Gile. Amsterdam: John Benjamins, 215-236. https://doi.org/10.1075/btl.80.17lam

Lambert, S. (2004). Shared attention during sight translation, sight interpretation and simultaneous interpretation. Meta 49 (2), 294-306. https://doi.org/10.7202/009352ar

Lemhöfer, K. \& Broersma, M. (2012). Introducing LexTALE: A quick and valid Lexical Test for Advanced Learners of English. Behavior Research Methods 44 (2), 325-343. https://doi.org/10.3758/s13428-011-0146-o

Lijewska, A. \& Chmiel, A. (2015). Cognate facilitation in sentence context - translation production by interpreting trainees and non-interpreting trilinguals. International Journal of Multilingualism 12 (3), 358-375. https://doi.org/10.1080/14790718.2014.959961

Maier, R.M., Pickering, M.J. \& Hartsuiker, R. J. (2017). Does translation involve structural priming? The Quarterly Journal of Experimental Psychology 70 (8), 1575-1589. https://doi.org/10.1080/17470218.2016.1194439

Malkiel, B. (2009). When idioti (idiotic) becomes "fluffy": Translation students and the avoidance of target-language cognates. Meta 54 (2), 309-325. https://doi.org/10.7202/037683ar

Mandera, P., Keuleers, E., Wodniecka, Z. \& Brysbaert, M. (2015). SUBTLEX-PL: subtitle-based word frequency estimates for Polish. Behavioral Research Methods 47 (2), 471-483. https://doi.org/10.3758/s13428-014-0489-4

Meuter, R.F.I. \& Allport, A. (1999). Bilingual language switching in naming: Asymmetrical costs of language selection. Journal of Memory and Language 40 (1), 25-40. https://doi.org/10.1006/jmla.1998.2602

Otwinowska, A. (2016). Cognate vocabulary in language acquisition and use: Attitudes, awareness, activation. Bristol: Multilingual Matters.

Pöchhacker, F. (1994). Simultaneous interpretation: 'Cultural transfer' or 'voice-over text'? In M. Snell-Hornby, F. Pöchhacker \& K. Kaindl (Eds.), Translation studies - an interdiscipline. Selected papers from the Translation Studies Congress, Vienna, 1992. Amsterdam: John Benjamins, 169-178. https://doi.org/10.1075/btl.2.22poc

Runnqvist, E., Strijkers, K., Alario, F.-X. \& Costa, A. (2012). Cumulative semantic interference is blind to language: Implications for models of bilingual speech production. Journal of Memory and Language 66 (4), 850-869. https://doi.org/10.1016/j.jml.2012.02.007

Sadoski, M. \& Paivio, A. (2013). A dual coding theoretical model of reading. In D. E. Alvermann, N. Unrau \& R. B. Ruddell (Eds.), Theoretical models and processes of reading (Sixth ed.). Newark, NJ: International Reading Association, 886-922. https://doi.org/10.1598/0710.34

Schneider, W., Eschman, A. \& Zuccolotto, A. (2002). E-Prime user's guide. Pittsburgh, PA: Psychology Software Tools Inc.

Seeber, K. G. (2011). Cognitive load in simultaneous interpreting: Existing theories - new models. Interpreting 13 (2), 176-204. https://doi.org/10.1075/intp.13.2.02see

Seeber, K. G. (2017a). Multimodal processing in simultaneous interpreting. In J.W. Schwieter \& A. Ferreira (Eds.), The handbook of translation and cognition. Hoboken, NJ: Wiley Blackwell, 461-475. https://doi.org/10.1002/9781119241485.ch25 
Seeber, K.G. (2017b). Interpreting at the European Institutions: Faster, higher, stronger. CLINA: Revista Interdisciplinaria de Traducción, Interpretación y Comunicación Intercultural 3 (2), 73-90. https://doi.org/10.14201/clina2017327390

Seleskovitch, D. \& Lederer, M. (1989). Pédagogie raisonnée de l'interprétation. Paris: Didier. Setton, R. (2003). Words and sense: Revisiting lexical processes in interpreting. Forum 1 (1), 139-168. https://doi.org/10.1075/forum.1.1.08set

Setton, R. \& Dawrant, A. (2016). Conference interpreting - a trainer's guide. Amsterdam: John Benjamins. https://doi.org/10.1075/btl.121

Shlesinger, M. (2008). Towards a definition of Interpretese: An intermodal, corpus-based study. In A. Chesterman, H. Gerzymisch-Arbogast \& G. Hansen (Eds.), Efforts and models in interpreting and translation research: A tribute to Daniel Gile. Amsterdam: John Benjamins, 237-253.

Shlesinger, M. \& Malkiel, B. (2005). Comparing modalities: Cognates as a case in point. Across Languages and Cultures 6 (2), 173-193. https://doi.org/10.1556/Acr.6.2005.2.2

Shreve, G. M., Lacruz, I. \& Angelone, E. (2010). Cognitive effort, syntactic disruption, and visual interference in a sight translation task. In G. M. Shreve \& E. Angelone (Eds.), Translation and cognition. Amsterdam: John Benjamins, 63-84. https://doi.org/10.1075/ata.xv.05shr

Spalek, K., Hoshino, N., Wu, Y. J., Damian, M. \& Thierry, G. (2014). Speaking two languages at once: Unconscious native word form access in second language production. Cognition 133 (1), 226-231. https://doi.org/10.1016/j.cognition.2014.06.016

Strobach, T. \& Schubert, T. (2017). Mechanisms of practice-related reductions of dual-task interference with simple tasks: Data and theory. Advances in Cognitive Psychology 13 (1), 28-41. https://doi.org/10.5709/acp-0204-7

Teich, E. (2003). Cross-Linguistic variation in system and text: A methodology for the investigation of translations and comparable texts. Berlin: De Gruyter Mouton. https://doi.org/10.1515/9783110896541

Tercedor, M. (2011). Cognates as lexical choices in translation: Interference in spaceconstrained environments. Target 22 (2), 177-193. https://doi.org/10.1075/target.22.2.01ter

Tindle, R. \& Longstaf, M.G. (2015). Writing, reading, and listening differentially overload working memory performance across the serial position curve. Advances in Cognitive Psychology 11 (4), 147-155. https://doi.org/10.5709/acp-0179-6

Titone, D., Libben, M., Mercier, J., Whitford, V. \& Pivneva, I. (2011). Bilingual lexical access during L1 sentence reading: The effects of L2 knowledge, semantic constraint, and L1-L2 intermixing. Journal of Experimental Psychology: Learning, Memory and Cognition 37 (6), 1412-1431.

Tymczyńska, M. (2012). Trilingual lexical processing in online translation recognition. The influence of conference interpreting experience. In D. Gabryś-Barker (Ed.), Crosslinguistic influences in multilingual language acquisition. Berlin: Springer, 151-167. https://doi.org/10.1007/978-3-642-29557-7_9

Van Assche, E., Duyck, W. \& Hartsuiker, R.J. (2012). Bilingual word recognition in a sentence context. Frontiers in Psychology 3, 1-8.

Van Heuven, W.J. B., Mandera, P., Keuleers, E. \& Brysbaert, M. (2014). SUBTLEX-UK: A new and improved word frequency database for British English. The Quarterly Journal of Experimental Psychology 67 (6), 1176-119o. https://doi.org/10.1080/17470218.2013.850521 
Verhoef, K., Roelofs, A. \& Chwilla, D. J. (2009). Role of inhibition in language switching: Evidence from event-related brain potentials in overt picture naming. Cognition 110 (1), 84-99. https://doi.org/10.1016/j.cognition.2008.10.013

Viezzi, M. (1989). Information retention as a parameter for the comparison of sight translation and simultaneous interpretation: An experimental study. The Interpreters' Newsletter 2, 65-69.

Wang, B. \& Zou, B. (2018). Exploring language specificity as a variable in Chinese-English interpreting. A corpus-based investigation. In M. Russo, C. Bendazzoli, \& B. Defrancq (Eds.), Making way in corpus-based Interpreting Studies. Singapore: Springer Singapore, 65-82. https://doi.org/10.1007/978-981-10-6199-8_4

Weinreich, U. (1953/1979). Languages in contact: Findings and problems. The Hague: Mouton. Wickens, C.D. (2002). Multiple resources and performance prediction. Theoretical Issues in Ergonomics Science 3 (2), 159-177. https://doi.org/10.1080/14639220210123806

\title{
Address for correspondence
}

\author{
Agnieszka Chmiel \\ Faculty of English \\ Adam Mickiewicz University \\ ul. Grunwaldzka 6 \\ 6o-78o Poznań \\ Poland \\ achmiel@amu.edu.pl
}

\section{Biographical notes}

Agnieszka Chmiel is Professor in the Department of Translation Studies, Faculty of English, Adam Mickiewicz University, Poznań, Poland. Her research interests include interpreting studies, lexical processing and memory in interpreting, reading in sight translation, audiovisual translation and audio description. She also works as a freelance conference interpreter.

Przemysław Janikowski is a former head of the Department of Translator and Interpreter Training at the College of Foreign Languages in Częstochowa, currently Assistant Professor at the University of Silesia and chief editor of the book series Ttumaczenie ustne - teoria, praktyka, dydaktyka devoted to researching interpreting in all its aspects. His research interests concentrate on psycho- and neurolinguistic aspects of interpreting, especially in didactic applications, including the role of interference in interpreting and the study of note-taking.

Anna Cieślewicz graduated from Adam Mickiewicz University in 2017 with a Master's degree in English. Her research focuses on psycholinguistics and language comprehension, and particularly on lexical processing in interpreting. 